\title{
Traumatic displacement of laser in situ keratomileusis flaps: an integrated clinical case presentation
}

\author{
Lu-Yang Shih, Kai-Ling Peng and Jiunn-Liang Chen ${ }^{*}$
}

\begin{abstract}
Background: Traumatic dislocation of laser-assisted in situ keratomileusis (LASIK) corneal flaps is an uncommon postoperative complication that could occur any time after LASIK, and could be visually devastating. We evaluated the visual outcomes, corneal sensation, tear function, and dry eye questionnaire results of patients with traumatic dislocation of LASIK flaps, including one LASIK flap amputation.

Methods: This is a retrospective case series. Seven patients who were diagnosed with traumatic displacement of the LASIK flap and underwent flap replacement surgery between August 2014 and January 2019 were included.Patient's visual acuity, refraction, corneal sensitivity, non-invasive tear breakup time (NIBUT), tear meniscus height (TMH), and ocular surface disease index (OSDI) results were evaluated.

Results: The patients' mean age was $35.86 \pm 5.84$ years, and $42.9 \%(3 / 7)$ were male. The mean duration from LASIK to trauma was $8.86 \pm 2.48$ years. The mean preoperative and postoperative six-month corrected distance visual acuity (CDVA) were $0.55 \pm 0.34$ and $0.02 \pm 0.03$, respectively. The mean spherical equivalent and astigmatism at six months postoperatively was $-1.0 \pm 0.95 \mathrm{D}$ and $-0.5 \pm 0.25 \mathrm{D}$, respectively. The corneal flap was clear and wellpositioned at the final follow-up (mean: $28.57 \pm 6.9$ months). $85.71 \%(6 / 7)$ of the patients showed worse corneal sensation in the injured eye. Interocular OSDI discrepancy was less in those whose last visit was more than 30 months after the trauma.
\end{abstract}

Conclusions: Postoperative CDVAat six months was improved, and the refractive data also showed some improvement. The corneal nerve and tear function recovery peaked before 30 months, while the OSDI continued to show a strong trend of improvement beyond 30 months.

Keywords: Laser in situ keratomileusis, Flap displacement, Flap amputation, Replacement surgery, Corneal sensitivity, Non-invasive tear breakup time, Tear meniscus height, Ocular surface disease index

\footnotetext{
* Correspondence: eyegogo@gmail.com

Department of Ophthalmology, Kaohsiung Veterans General Hospital, 386,

Ta-Chung 1st Road, 813 Kaohsiung City, Taiwan
}

(C) The Author(s). 2021 Open Access This article is licensed under a Creative Commons Attribution 4.0 International License, which permits use, sharing, adaptation, distribution and reproduction in any medium or format, as long as you give appropriate credit to the original author(s) and the source, provide a link to the Creative Commons licence, and indicate if changes were made. The images or other third party material in this article are included in the article's Creative Commons licence, unless indicated otherwise in a credit line to the material. If material is not included in the article's Creative Commons licence and your intended use is not permitted by statutory regulation or exceeds the permitted use, you will need to obtain permission directly from the copyright holder. To view a copy of this licence, visit http://creativecommons.org/licenses/by/4.0/ The Creative Commons Public Domain Dedication waiver (http://creativecommons.org/publicdomain/zero/1.0/) applies to the data made available in this article, unless otherwise stated in a credit line to the data. 


\section{Background}

Laser-assisted in situ keratomileusis (LASIK) has become one of the most common and popular corrective techniques for refractive error. However, LASIK is associated with potential postoperative complications, including over- and under-correction, dry eye, corneal sensation impairment, infection, epithelial ingrowth, corneal flaprelated problems, and cornea ectasia [1]. Traumatic displacement or amputation of LASIK corneal flaps is an uncommon postoperative complication that can occur any time after LASIK [2, 3] and could be visually devastating $[4,5]$. Successful replacement of an amputated LASIK corneal flap has only been reported once, in a case of blunt eye injury five months following LASIK [6].

Replacing the traumatic corneal flap of LASIK as soon as possible is the most effective way to restore the patient's vision. Several studies on the results of traumatic corneal flap replacement have been published but are mostly limited to case studies. Here, we present seven cases of traumatic displacement of LASIK corneal flaps that underwent replacement surgery. This case series provides detailed information on the outcomes and evaluations conducted, which have seldom been focused on in previous reports. We also conducted a literature review to add to our discussion.

\section{Methods}

This retrospective study complied with the tenets of the Declaration of Helsinki and was approved by the Ethics Board of Kaohsiung Veterans General Hospital. As this was a retrospective study, written informed consent from the patients was not required. We retrospectively reviewed the clinical charts of 12 consecutive patients who presented to our hospital with traumatic displacement of their LASIK corneal flap between August 2014 and January 2019. The inclusion criteria were patients who underwent LASIK before having eye trauma with dislocation of the corneal flap, underwent flap replacement surgery, and were followed-up for at least six months. The exclusion criteria were patients with selfreported amblyopia, traumatic LASIK flap displacement who lost their flap, did not undergo flap replacement surgery,and were followed-up for less than six months. Of the 12 patients, two patients did not undergo replacement surgery due to extensive scarring of the flap interface, two patients were lost to follow-up within six months, and one patient lost his flap. Therefore, seven patients were included in this case series.

We recorded each patient's baseline demographic and medical information, including sex, age, the side of the affected eye (left or right), the mechanism of eye trauma, interval between the LASIK surgery and eye trauma, and the interval between the eye trauma and corneal flap replacement. We recorded the preoperative and postoperative one, three, and six-month corrected distance visual acuity (CDVA) and postoperative one, three, and six-month refractive data, including the spherical and keratometry measurements. CDVA was measured using Snellen charts. We further recorded the ocular surface disease index (OSDI) questionnaire results, tear meniscus height $(\mathrm{TMH})$, non-invasive tear breakup time (NIBUT), and corneal sensation at the last visit of all patients. For corneal sensation, we used a Cochet-Bonnet esthesiometer. NIBUT and TMH were evaluated using an IDRA $^{\circ}$ Ocular surface analyzer (SBM Sistemi, Italy).

During replacement surgery, a sterile surgical sponge was used to completely remove any surface debris, and the surface was irrigated with a balanced salt solution (BSS). The intact part of the corneal flap was demarcated and dissected from the peripheral corneal flap toward the central stromal bed. The entire corneal flap was lifted with a LASIK spatula and was then folded back at the hinge to expose the entire stromal bed. Next, the flap was flattened with a sterile surgical sponge. Debris and epithelial cells were scraped from the stromal bed and undersurface and vigorously irrigated with BSS to remove the epithelial cells and remnants that adhered to the interface. The corneal flap was then replaced and stretched by surgical sponges to avoid folds or wrinkles. In cases where the corneal flap could not evenly adhere to the stromal bed, corneal sutures with $10-0$ nylon was performed. Finally, a bandage soft contact lens was placed on the cornea for protection. Postoperatively, $1 \%$ prednisolone acetate and levofloxacin antibiotic eye drops were administered every $2 \mathrm{~h}$ initially and then gradually tapered over the follow-up period.

We defined the primary outcome as the CDVAand refraction status six months postoperatively, including the spherical equivalents and astigmatism. The secondary outcomes were defined as the OSDI, corneal sensation, $\mathrm{TMH}, \mathrm{NIBUT}$ of the injured eye, and the interocular discrepancy of the OSDI, corneal sensation, TMH, and NIBUT at the last visit. The follow-up intervals from the replacement surgeries to the last visit ranged from six to 58 months. We used the median follow-up interval of 30 months to divide the patients into two secondary outcome comparison groups.

For statistical analysis, the Snellen visual acuity was converted to the logarithm of the minimum angle of resolution $(\log M A R)$ visual acuity. The variables considered were sex, the side of the affected eye (left or right), the use of flap sutures, the assistance of a femtosecond laser during LASIK, age, the interval between LASIK and trauma, and the interval between trauma and replacement surgery. The patients were divided into two groups according to their follow-up interval and compared to each otherfor their corneal sensitivity, NIBUT, 
TMH, and OSDI results of the last visit. The data were analyzed using IBM SPSS statistical software version 20.0 .

\section{Results}

Seven patients underwent LASIK flap replacement surgery after traumatic corneal flap dislocation. The preoperative and postoperative patient demographic data are shown in Tables 1 and 2. The patients' mean age was $35.86 \pm 5.84$ years. Of the patients, $42.9 \%(3 / 7)$ were male. Femtosecond-assisted LASIK was performed on $28.57 \%(2 / 7)$ of the patients. The mean duration from LASIK surgery to eye trauma was $8.86 \pm 2.48$ years. The mean interval from eye trauma to corneal flap replacement surgery was $33.86 \pm 60.73 \mathrm{~h}$. The main mechanism of eye trauma was blunt trauma $(100 \%, 7 / 7)$. At the end of corneal flap replacement surgery, $71.43 \%(5 / 7)$ required a corneal flap suture. The rate of epithelial ingrowth was $14.3 \%$ (1/7); no other complications were seen.

We present the mean preoperative and postoperative CDVAresults at one, three, and six months in Fig. 1. The mean preoperative and postoperative CDVA at one, three, and six months in $\log$ MAR were $0.55 \pm 0.34$, $0.15 \pm 0.17,0.06 \pm 0.06$, and $0.02 \pm 0.03$, respectively. In the primary outcome analysis, the CDVA change from preoperatively to six months postoperatively was remarkable $(P=0.018$, Wilcoxon signed rank test). The CDVAalso showed a trend of improvement at one month $(P=0.018$, Wilcoxon signed rank test $)$ and three months postoperatively $(P=0.018$, Wilcoxon signed rank test) when respectively compared to the preoperative value. The postoperative spherical changes are shown in Fig. 2. The mean spherical equivalent at one, three, and six months postoperatively were $-0.46 \pm 2.52 \mathrm{D},-0.68 \pm$ $0.87 \mathrm{D}$, and $-1.0 \pm 0.95 \mathrm{D}$, respectively. The postoperative astigmatism changes are shown in Fig. 3. The mean astigmatism at one, three, and six months postoperatively were $-1.46 \pm 2.23 \mathrm{D},-0.61 \pm 0.43 \mathrm{D}$, and $-0.5 \pm$ $0.25 \mathrm{D}$, respectively. The mean interval from replacement surgery to the last visit was $28.57 \pm 6.9$ months. At the last visit, corneal sensation, NIBUT, and TMH values were lower in the injured eye in $85.71 \%(6 / 7)$, $42.86 \%(3 / 7)$, and $42.86 \%(3 / 7)$ of the patients, respectively. In our secondary outcome analysis, the mean corneal sensation,the mean NIBUT, and the mean OSDI were lower in the longer follow-up group $(51.67 \mathrm{~mm}$ versus $48.75 \mathrm{~mm}, 14.43 \mathrm{~s}$ versus $9.98 \mathrm{~s}$, and 28.47 versus 19.27, respectively);the mean $\mathrm{TMH}$, however, was higher in the longer follow-up group $(0.13 \mathrm{~mm}$ versus $0.17 \mathrm{~mm})$.The mean interocular discrepancy of the corneal sensation, of the NIBUT, and of the OSDI showed less difference in the longer follow-up group $(-6.67 \mathrm{~mm}$ versus $-3.75 \mathrm{~mm},-0.23 \mathrm{~s}$ versus $-0.13 \mathrm{~s}$, and 18.06 versus 7.29 , respectively); the mean interocular discrepancy of the TMH was higher in the longer follow-up group $(0.007 \mathrm{~mm}$ versus $0.015 \mathrm{~mm})$.It is worth noting that the interocular OSDI discrepancy showed marked difference between the two groups $(P=0.048$, Mann-Whitney $\mathrm{U}$ test) (Table 3$)$.

Case one was a 29-year-old male who presented to the emergency department with right eye blunt trauma that occurred during a basketball game. He had a history of LASIK in both eyes four years prior. The corneal flap was amputated and found on his forearm after the injury, which was brought to our emergency department within an hour (Fig. 4a). The refraction was - 0.75$2.25 \times 30$ in his right eye. The amputated cornea flap

Table 1 The pre- and postoperative characteristics of the study population

\begin{tabular}{|c|c|c|c|c|c|c|c|c|c|c|c|}
\hline $\begin{array}{l}\text { Case } \\
\text { No. }\end{array}$ & Sex & Eye & $\begin{array}{l}\text { Age } \\
\text { (Years) }\end{array}$ & $\begin{array}{l}\text { Interval } \\
\text { between } \\
\text { LASIK and } \\
\text { trauma } \\
\text { (years) }\end{array}$ & $\begin{array}{l}\text { Interval } \\
\text { between } \\
\text { trauma and } \\
\text { replacement } \\
\text { (hours) }\end{array}$ & $\begin{array}{l}\text { Mechanism } \\
\text { of trauma } \\
\text { (Etiology) }\end{array}$ & $\begin{array}{l}\text { Preoperative } \\
\text { CDVA } \\
\text { logMAR }\end{array}$ & $\begin{array}{l}\text { Flap } \\
\text { suture }\end{array}$ & $\begin{array}{l}\text { Postoperative } \\
\text { six month } \\
\text { CDVA } \\
\text { logMAR }\end{array}$ & $\begin{array}{l}\text { OSDI score } \\
\text { discrepancy }\end{array}$ & Complications \\
\hline 1 & M & $\mathrm{OD}$ & 29 & 4 & 7 & $\begin{array}{l}\text { Blunt } \\
\text { (Forearm) }\end{array}$ & 1.00 & - & 0.00 & 10.42 & - \\
\hline 2 & $\mathrm{~F}$ & $\mathrm{OD}$ & 34 & 11 & 42 & $\begin{array}{l}\text { Blunt } \\
\text { (Car accident) }\end{array}$ & 0.77 & + & 0.30 & 8.33 & - \\
\hline 3 & $\mathrm{~F}$ & OS & 38 & $10^{\mathrm{a}}$ & 3 & $\begin{array}{l}\text { Blunt } \\
\text { (Finger) }\end{array}$ & 0.30 & + & 0.00 & 12.5 & - \\
\hline 4 & M & OS & 29 & 7 & 168 & $\begin{array}{l}\text { Blunt } \\
\text { (Dog paw) }\end{array}$ & 0.18 & + & 0.00 & 18.75 & - \\
\hline 5 & $\mathrm{~F}$ & $\mathrm{OD}$ & 43 & $10^{\mathrm{a}}$ & 5 & $\begin{array}{l}\text { Blunt } \\
\text { (pen) }\end{array}$ & 0.77 & + & 0.05 & 22.92 & $\begin{array}{l}\text { epithelial } \\
\text { ingrowth }\end{array}$ \\
\hline 6 & $\mathrm{~F}$ & OS & 43 & 10 & 8 & $\begin{array}{l}\text { Blunt } \\
\text { (Desk pad) }\end{array}$ & 0.70 & - & 0.00 & 4.17 & - \\
\hline 7 & M & OS & 35 & 10 & 4 & $\begin{array}{l}\text { Blunt } \\
\text { (Desk corner) }\end{array}$ & 0.15 & + & 0.05 & 6.25 & - \\
\hline
\end{tabular}

${ }^{a}$ Femtosecond-assisted LASIK; No. number, $M$ male, $F$ female, LASIK laser-assisted in situ keratomileusis, CDVA corrected distance visual acuity, logMAR logarithm of minimum angle of resolution, OSDI ocular surface disease index, SD standard deviation, $M$ male, $F$ female 
Table 2 Preoperative data of patients with traumatic LASIK flap dislocation

\begin{tabular}{ll}
\hline & Total, $\boldsymbol{n = 7}$ \\
\hline Male, n (\%) & $3(42.9)$ \\
OD, n (\%) & $3(42.9)$ \\
Age (mean, SD), years & $35.86(5.84)$ \\
Interval of LASIK and trauma (mean, SD), years & $8.86(2.48)$ \\
Interval of trauma and replacement surgery (mean, SD), & 33.86 \\
hours & $(60.73)$ \\
Flap suture, n (\%) & $5(71.4)$ \\
Femtosecond-assisted LASIK, n (\%) & $2(28.57)$ \\
Preoperative logMAR CDVA, (mean, SD) & $0.55(0.34)$ \\
Postoperative 6 months logMAR CDVA, (mean SD) & $0.02(0.03)$ \\
Complication, n (\%) & $1(14.3)$ \\
\hline
\end{tabular}

$n$ number, SD standard deviation, LASIK laser-assisted in situ keratomileusis, pre-op preoperative, post-op postoperative six months, CDVA corrected distance visual acuity, logMAR logarithm of the minimum angle of resolution

was then soaked in half concentrated aseptic hypotonic BSS solution for temporary storage and was then submerged in half beta-iodine solution for 1 min just before surgery. LASIK flap replacement was performed without sutures. A therapeutic soft contact lens was applied at the end of the surgery. At one month postoperatively, his CDVA improved to logMAR0 with a refraction of + $1.00 /-0.75 \times 93$. At 6 months postoperatively, the corneal flap was clear in the center, in a good position, and without any epithelial ingrowth (Fig. 4b).

Case four was a 29-year-old male patient who presented at our clinic after a dog's paw had injured his left eye seven days prior. He had been initially treated with topical antibiotics at a local clinic. He had undergone LASIK seven years prior. CDVA of the injured eye was $\operatorname{logMAR0.15}$, with a refraction of $+4.50-6.50 \times 90$. Slit-



Fig. 1 The mean preoperative CDVA was $0.55 \log M A R$. The mean CDVA at one month postoperatively had significantly improved to 0.15 $\operatorname{logMAR}(p=0.018)$; the mean CDVA at three months postoperatively also significantly improved to $0.06 \log M A R(p=0.018)$, and the mean CDVA at 6 months postoperatively remained stable at $0.02 \log M A R$. logMAR: logarithm of the minimum angle of resolution

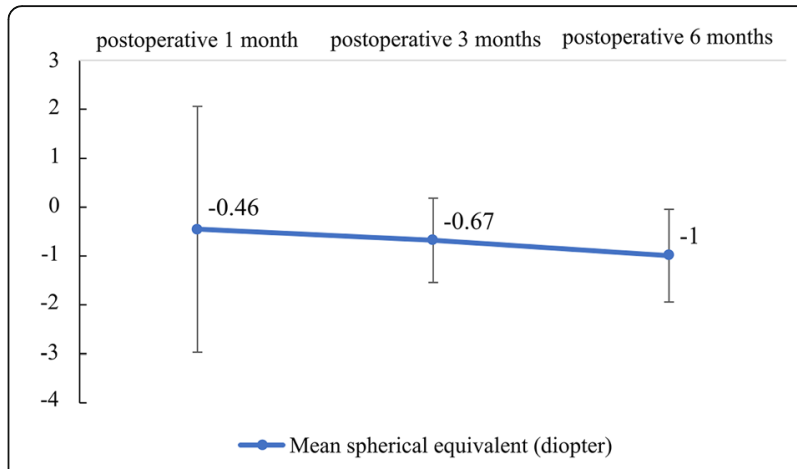

Fig. 2 The mean spherical equivalent at one, three, and six months was $-0.46 \pm 2.52 D,-0.68 \pm 0.87 D$, and $-1.0 \pm 0.95 D$, respectively

lamp examination showed a temporal-inferiorly infolded corneal flap with epithelial ingrowth (Fig. 5a and b). Anterior segment optical coherence tomography (ASOCT) showed an infolded flap, with re-epithelialization over the bare stroma and epithelial ingrowth between the flap interface (Fig. 5c). He underwent LASIK flap replacement with mitomycin-C irrigation of the flap interface and suture fixation of the flap. At six months postoperatively, his uncorrected distance visual acuity (UDVA) improved to $\log$ MAR0 with a refraction of $-1.25-0.75 \times 90$, and the corneal flap was still clear in the central cornea (Fig. 6a and b).

\section{Discussion}

LASIK flaps have shown tremendous stability during severe mechanical ocular trauma [7]. However, traumatic flap dislocation can still occur. Several case reports, but few case series, have been published on the traumatic dislocation of the LASIK flap. Xiao et al. described 45 cases of late traumatic flap complications after LASIK, where flap displacement accounted for $71 \%$. However, only $55 \%$ underwent flap replacement [8]. Tsai et al. further reviewed published studies on late-onset traumatic flap displacement after LASIK, and $94.74 \%$ of patients

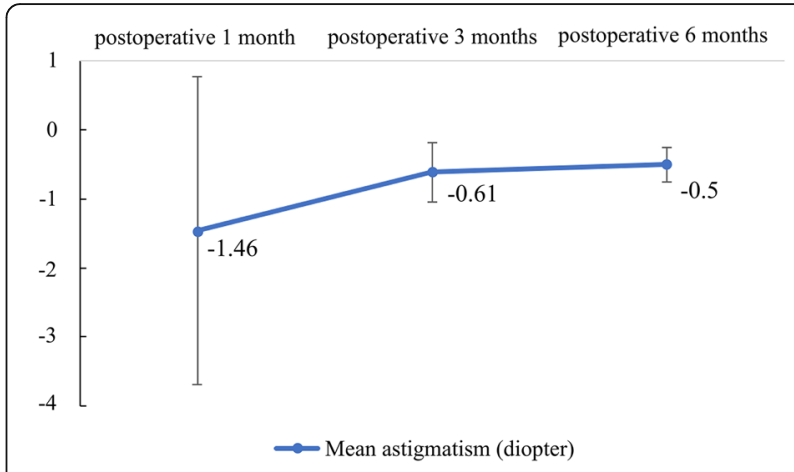

Fig. 3 The mean astigmatism at one, three, and six months was $1.46 \mathrm{D},-0.61 \mathrm{D}$, and $-0.5 \mathrm{D}$, respectively 
Table 3 Summary of the secondary outcome analysis

\begin{tabular}{lll}
\hline & $\begin{array}{l}\text { Follow-up interval < } \\
\boldsymbol{n}=\mathbf{3 0}\end{array}$ & $\begin{array}{l}\text { months (mean SD) } \\
\boldsymbol{n}=\mathbf{4}\end{array}$ \\
\hline Corneal sensation of the injured eye (mean SD), mm & $51.67(2.89)$ & $48.75(6.29)$ \\
NIBUT of the injured eye (mean SD), sec & $14.43(10.42)$ & $9.98(2.68)$ \\
TMH of the injured eye (mean SD), mm & $0.13(0.03)$ & $0.17(0.07)$ \\
OSDI of the injured eye (mean SD) & $28.47(7.89)$ & $19.27(10.54)$ \\
Corneal sensation discrepancy (mean SD), mm & $-6.67(2.89)$ & $-3.75(2.50)$ \\
NIBUT discrepancy (mean SD), sec & $-0.23(3.31)$ & $-0.13(0.41)$ \\
TMH discrepancy (mean SD), mm & $0.007(0.015)$ & $0.015(0.034)$ \\
OSDI discrepancy(mean SD) & $18.06(5.24)$ & $7.29(2.69)$ \\
\hline
\end{tabular}

$n$ number, SD standard deviation, $m m$ millimeter, NIBUT non-invasive tear break-up time, TMH tear meniscus height, OSDI ocular surface disease index

had an ocular trauma score of grade 1, visual acuity better than $\log$ MAR0.3, after proper treatment [9]. In our study, all patients underwent replacement surgery, and the one patient that experienced epithelial ingrowth complications a month later underwent debridement and achieved a final UDVAof logMAR0.05. We analyzed the mean postoperative CDVAchanges at different times and found that the mean CDVAat one month postoperatively, $0.15 \pm 0.17 \log$ MAR, had improved greatly from the mean preoperative CDVA, $0.55 \pm 0.34 \log$ MAR. The mean CDVAgradually improved to $0.06 \pm 0.06$ at three months postoperatively, and then mildly improved to a mean CDVA of $0.02 \pm 0.03$ at six months postoperatively. The spherical equivalent changed from $-0.46 \mathrm{D}$ at one month postoperatively to $-1.0 \mathrm{D}$ at six months postoperatively. Furthermore, the astigmatism improved from $-1.46 \mathrm{D}$ at one month postoperatively to $-0.5 \mathrm{D}$ at six months postoperatively.

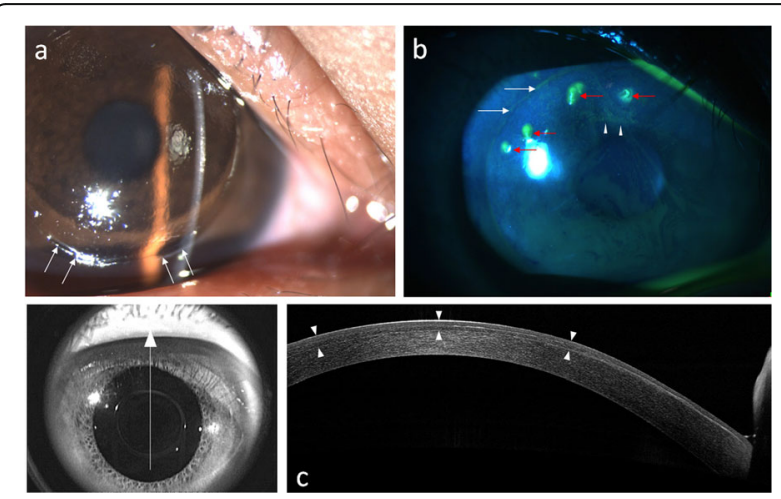

Fig. 4 Slit-lamp photography of a post-laser in situ keratomileusis eye with flap amputation. The white arrows indicate the bare stromal edge (a). At eight months postoperatively, corneal fluorescent staining shows a well-re-positioned flap with only mild uptake along the flap edge (white arrows). Filaments (red arrows) with dry spots (white arrowheads) are shown in (b). At eight months postoperatively, anterior segment optical coherence tomography showed that the flap was slightly thicker at the inferior periphery than the central and superior portions (c)
Haw et al. reported a case of complete traumatic flap amputation five months after LASIK. The amputated flap was successfully replaced even after being on the ground for $8 \mathrm{~h}$. The UDVAhad improved to logMAR0.1 at eight months postoperatively [6]. Case one in our study also had total traumatic flap amputation at the hinge. The flap was found on his forearm and was replaced back to the stromal bed $7 \mathrm{~h}$ later. The preoperative refraction was compound myopic with the rule astigmatism with $-0.75-2.25 \times 30$. The UDVA improved to $\operatorname{logMAR0}$ with a refraction of $+0.5-0.5 \times 80$ at six months postoperatively. ASOCT showed that the flap was slightly thicker at the inferior periphery and gradually became thinner at the central and superior portions (Fig. 4c). The myopic shift after amputation and the subsequent shift back toward emmetropia after replacement surgery may be due to the negative meniscus morphology of the LASIK flap. Lin et al. demonstrated a case of traumatic LASIK flap loss resulting in a myopic shift in refraction. This was attributed to the flap and stromal bed structure. A minus meniscus flap was created using a conventional microkeratome during LASIK. After flap loss, the underlying stromal bed with a steeper curvature would be revealed, causing a myopic change [10]. The postoperative refraction changes and ASOCT image in case one were consistent with the postulation that the refraction change would reflect the flap morphology. In case one, the final clinical outcome also shows that replacement surgery should always be attempted in cases with flap amputation whenever possible. The visual and refractive outcome may be comparable with patients without amputation.

In LASIK surgery, the superficial corneal stromal nerves may be damaged in two pathways. One is direct transection at the flap margin, while the other is due to exposure to excimer laser photoablation, which may vary according to the desired myopic correction. The regeneration of nerve fibers begins from the nerves distal to the surgically induced corneal wound, and the proximal 

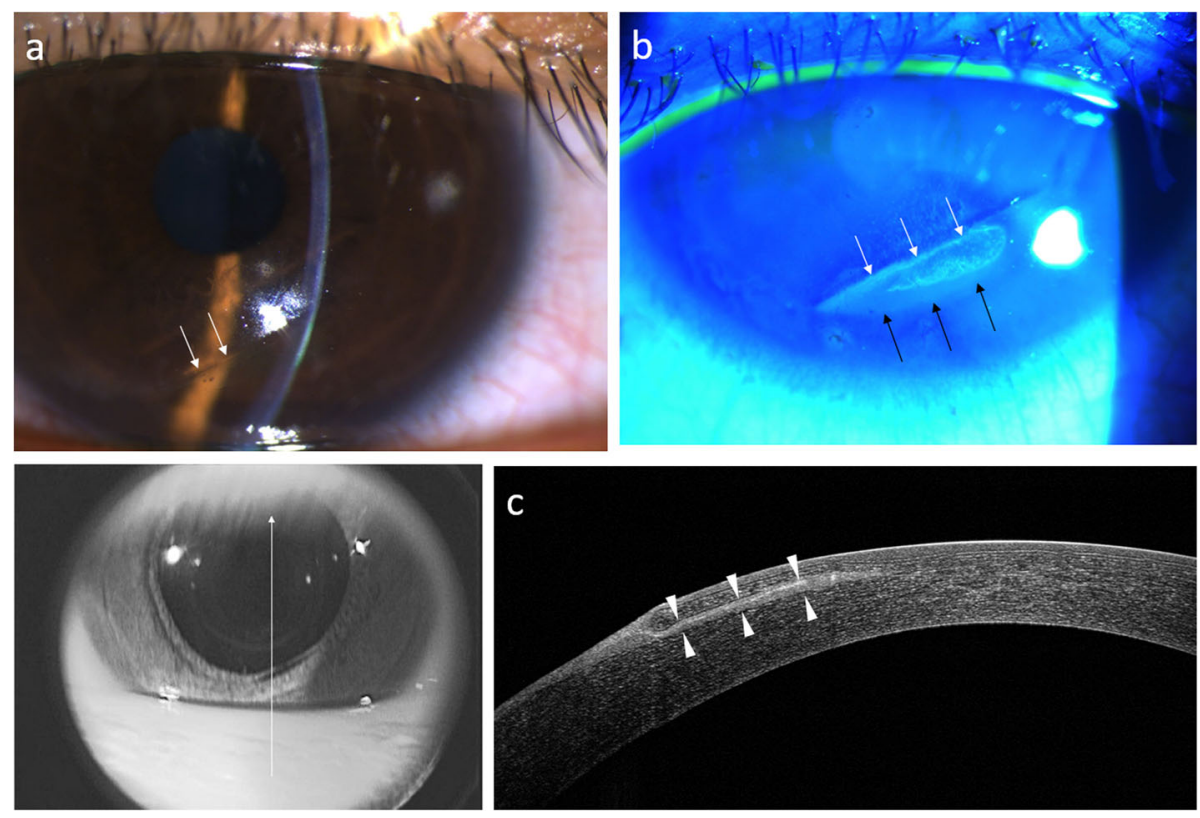

Fig. 5 Slit-lamp photography of case four shows laser in situ keratomileusis flap edge infolding at 3-7 clock hours on day seven post-trauma. The infolding ridge is visualized by retro-illumination (white arrows; a). Fluorescence staining of the same case. The white and black arrows demonstrate re-epithelialization over the bare stroma $(\mathbf{b})$. Anterior segment optical coherence tomography shows an infolded flap, with reepithelial over the bare stroma and epithelial ingrowth (white arrows) between the flap interface (c)

trunks will then send regenerating nerve fibers toward the wounded area [11]. The flap contains an undisturbed Bowman's layer and the original Schwann cell pathways from the hinge, which might facilitate the recovery process of the nerve. Bragheeth et al. concluded that central corneal sensitivity is decreased for at least six months after LASIK. The corneal sensation does not directly correlate with the regeneration of nerve fibers, as determined by confocal imaging [12]. However, disturbance of the sensory reflex arch between the cornea and lacrimal system may account for the dry eye symptoms and signs in a number of patients after LASIK. Siganos et al. found that tear secretion following LASIK was decreased at three months after surgery and was normalized by six months [13]. When traumatic displacement of the LASIK flap occurs, the previously regenerated nerves areonce again mechanically transected. A second round of nerve regeneration takes place after replacement surgery.Sauvageot et al. demonstrated that the corneal sensitivity and TBUT of patients who received femtosecond-assisted LASIK returned to preoperative values one year after refractive surgery [14]. Shaaban et al. demonstrated that the TMH returned to preoperative levels one and six months postoperatively in those that underwent femtosecond small incision lenticule extraction and femtosecond-assisted LASIK, respectively [15]. Tao et al. also demonstrated that the upper and lower tear menisci after LASIK recovered to the preoperative level by 20 months [16].

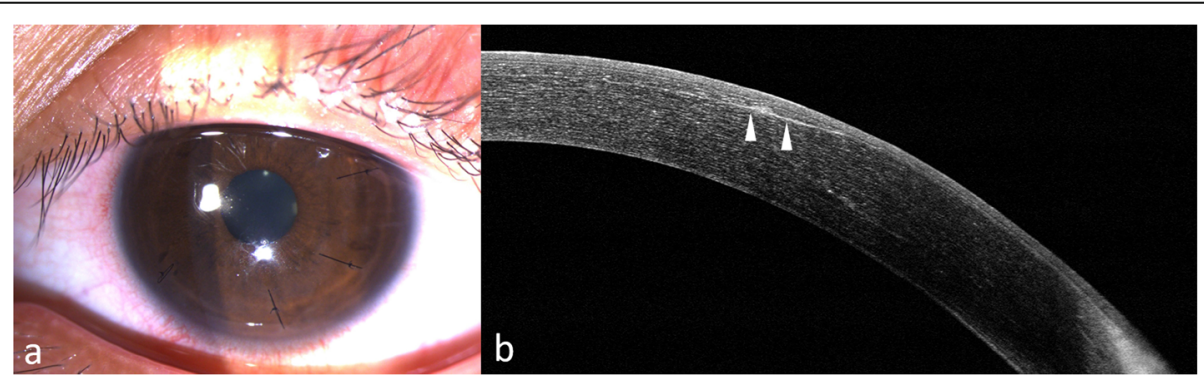

Fig. 6 Slit-lamp photography of case four at two weeks postoperatively shows a well-replaced flap secured with sutures (a). Anterior segment optical coherence tomography at six months postoperatively shows minimal interface scarring (arrowheads) (b) 
In our study, up to $85.71 \%(6 / 7)$ of the patients showed worse corneal sensation in the injured eye after a mean period of 28.57 months (range, 6-58 months). Among the secondary outcomes at the last visit, interocular discrepancy of the OSDI was the only one that showed a marked difference between the two groups. According to the previous studies mentioned above, the corneal sensitivity, NIBUT, and $\mathrm{TMH}$ of the injured eye may have reached their maximum recovery status before 30 months in both groups, and therefore would not show meaningful differences. The rate of higher OSDI score in the injured eye was $100 \%$ (7/ 7), but the interocular OSDI discrepancy was notably less in the group with a follow-up interval of more than 30 months. These results show that even though recovery of the corneal nerve and tear function peaked within 30 months, comfort improvements could still be observed beyond 30 months. In other words, although the nerve function and tear characteristics recovery peaked, a longer time was required for symptom relief.

\section{Conclusions}

In conclusion, several reports on the results of corneal flap replacement after the traumatic dislocation of LASIK flaps have been previously published. However, few have evaluated corneal sensation and tear function following flap replacement. In the primary outcome analysis, the postoperative CDVAat six months was found to have remarkably improved, and the astigmatism also showed some improvement. In the secondary outcome analysis, the recovery of the corneal nerve and tear function reached its peak before 30 months, while the OSDI continued to show a strong trend of improvement beyond 30 months. This study had several limitations, including its retrospective design and small sample size.

\footnotetext{
Abbreviations

LASIK: Laser in situ keratomileusis; NIBUT: Non-invasive tear breakup time; TMH: Tear meniscus height; OSDI: Ocular surface disease index; CDVA: Corrected distance visual acuity; UDVA: Uncorrected distance visual acuity; LogMAR: Logarithm of the minimum angle of resolution; BSS: Balanced salt solution; ASOCT: Anterior segment optical coherence tomography; SMILE: Small incision lenticule extraction
}

\section{Acknowledgements}

The authors would like to express their appreciation to the Department of Medical Education and Research and Research Center of Medical Informatics in Kaohsiung Veterans General Hospital and professor Chao-Hsien, Lee for addressing our inquiries and for providing their assistance with processing the data included in our study.

\section{Authors' contributions}

LYS collected clinical data. LYS and KLP wrote the statistical analysis plan, analyzed the data and drafted the paper. JLC was responsible for clinical treatment of the patients. LYS and KLP initiated this study, designed data collection tools and implemented the study. All authors read and approved the final manuscript.

\section{Funding}

All authors declare that they received no public or private support in relation to this paper and have no conflicts of interest to declare.

\section{Availability of data and materials}

This study is based in part on data from the Department of Medical Education and Research and Research Center of Medical Informatics in Kaohsiung Veterans General Hospital. The datasets used and/or analyzed during the current study are available from the corresponding author on reasonable request.

\section{Declarations}

Ethics approval and consent to participate

The study and ethics were both approved by the Kaohsiung Veteran General Hospital's Institutional Review Board. The data in this study was all anonymized from the Department of Medical Education and Research and Research Center of Medical Informatics in Kaohsiung Veterans General Hospital. Written informed consent from patients was waived according to the Kaohsiung Veteran General Hospital's Institutional Review Board guideline: Written informed consent may be waived in full if the retrospective study involves no more than minimal risk, and if the waiver will not adversely affect the rights and welfare of the subjects.

\section{Consent for publication}

Not applicable.

\section{Competing interests}

All authors declare that they have any financial or non-financial competing interests.

Received: 8 February 2021 Accepted: 5 April 2021

Published online: 13 April 2021

\section{References}

1. Estopinal CB, Mian SI. LASIK flap: postoperative complications. Int Ophthalmol Clin 2016; 56(2):67-81.

2. Sinha R, Shekhar H, Tinwala S, Gangar A, Titiyal JS. Late post-traumatic flap dislocation and macrostriae after laser in situ keratomileusis. Oman J Ophthalmol 2014; 7(1):25-7.

3. Moshirfar M, Anderson E, Taylor N, Hsu M. Management of a traumatic flap dislocation seven years after LASIK. Case Rep Ophthalmol Med 2011; 2011: 514780.

4. Tetz M, Werner L, Muller M, Dietze U. Late traumatic LASIK flap loss during contact sport. J Cataract Refract Surg 2007; 33(7):1332-5.

5. Galvis V, Tello A, Ortiz Al, Quintero MP, Parra MM, Blanco NA. Traumatic corneal flap avulsion and loss 13years after LASIK. Saudi J Ophthalmol 2019; 33(2):172-6.

6. Haw WW, Manche EE. Successful corneal flap replacement following complete traumatic flap amputation after laser-assisted in situ keratomileusis. Arch Ophthalmol 2004; 122(2):275-6.

7. Todd T, Mondzelewski T, Cason J, Hofmeister E, O'Connell S, Richmond C. LASIK flap stability after severe ocular injury. Am J Ophthalmol Case Rep 2020; 18:100608.

8. Xiao J, Jiang C, Zhang M, Jiang H, Li S, Zhang Y. When case report became case series: 45 cases of late traumatic flap complications after laser-assisted in situ keratomileusis and review of Chinese literature. Br J Ophthalmol 2014; 98(9):1282-6.

9. Tsai TH, Peng KL, Lin CJ. Traumatic corneal flap displacement after laser in situ keratomileusis (LASIK). Int Med Case Rep J 2017; 10:143-8.

10. Lin MY, Chang DC, Hsiao JC, Wang IJ. Refractive change and photorefractive keratectomy treatment for a late traumatic flap loss. Clin Exp Optom 2010; 93(3):175-9.

11. de Leeuw AM, Chan KY. Corneal nerve regeneration. Correlation between morphology and restoration of sensitivity. Invest Ophthalmol Vis Sci 1989; 30(9):1980-90.

12. Bragheeth MA, Dua HS. Corneal sensation after myopic and hyperopic LASIK: clinical and confocal microscopic study. Br J Ophthalmol 2005; 89(5):580-5.

13. Siganos DS, Popescu CN, Siganos CS, Pistola G. Tear secretion following excimer laser in situ keratomileusis. J Refract Surg 2002; 18(2):124-6.

14. Sauvageot P, Julio G, Alvarez de Toledo J, Charoenrook V, Barraquer RI. Femtosecond laser-assisted laser in situ keratomileusis versus photorefractive keratectomy: effect on ocular surface condition. J Cataract Refract Surg 2017; 43(2):167-73. 
15. Shaaban YM, Badran TAF. Tear meniscus evaluation after microkeratome laser in situ keratomileusis, femtosecond laser and femtosmile laser techniques using anterior segment optical coherence tomography. Clin Ophthalmol 2018; 12:1337-45.

16. Tao A, Shen M, Wang J, Chen Q, Lu F. Upper and lower tear menisci after laser in situ keratomileusis. Eye Contact Lens 2010;36(2):81-5.

\section{Publisher's Note}

Springer Nature remains neutral with regard to jurisdictional claims in published maps and institutional affiliations.

Ready to submit your research? Choose BMC and benefit from:

- fast, convenient online submission

- thorough peer review by experienced researchers in your field

- rapid publication on acceptance

- support for research data, including large and complex data types

- gold Open Access which fosters wider collaboration and increased citations

- maximum visibility for your research: over $100 \mathrm{M}$ website views per year

At BMC, research is always in progress.

Learn more biomedcentral.com/submissions 